\title{
Serum 25-Hydroxyvitamin D Concentrations and Atopic Dermatitis in Early Childhood: Findings from the Japan Environment and Children's Study
}

\author{
Limin Yang 1,2,*D, Miori Sato ${ }^{1,2}$, Mayako Saito-Abe ${ }^{1,2}$, Minaho Nishizato ${ }^{1,2}$, Hidetoshi Mezawa ${ }^{1,2} \mathbb{D}$,

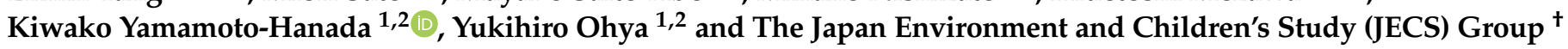 \\ $1 \quad$ Allergy Center, National Center for Child Health and Development, Tokyo 157-8535, Japan; \\ sato-m@ncchd.go.jp (M.S.); saito-myk@ncchd.go.jp (M.S.-A.); nishizato-m@ncchd.go.jp (M.N.); \\ mezawa-h@ncchd.go.jp (H.M.); yamamoto-k@ncchd.go.jp (K.Y.-H.); ohya-y@ncchd.go.jp (Y.O.) \\ 2 Medical Support Center for the Japan Environment and Children's Study, \\ National Research Institute for Child Health and Development, Tokyo 157-0074, Japan \\ * Correspondence: yo-r@ncchd.go.jp; Tel.: +81-3-3416-0181; Fax: +81-3-3416-2222 \\ + Membership of the JECS Group is Provided in the Acknowledgments.
}

Citation: Yang, L.; Sato, M.; Saito-Abe, M.; Nishizato, M.; Mezawa, H.; Yamamoto-Hanada, K.; Ohya, Y.; The Japan Environment and Children's Study (JECS) Group. Serum 25-Hydroxyvitamin D Concentrations and Atopic Dermatitis in Early Childhood: Findings from the Japan Environment and Children's Study. Nutrients 2021, 13, 2761. https://doi.org/10.3390/ nu13082761

Academic Editor: Andrea Fabbri

Received: 4 July 2021

Accepted: 10 August 2021

Published: 12 August 2021

Publisher's Note: MDPI stays neutral with regard to jurisdictional claims in published maps and institutional affiliations.

Copyright: (c) 2021 by the authors. Licensee MDPI, Basel, Switzerland. This article is an open access article distributed under the terms and conditions of the Creative Commons Attribution (CC BY) license (https:// creativecommons.org/licenses/by/ $4.0 /)$.
Abstract: Vitamin D (VitD) may affect immune system modulation and result in the development of atopic dermatitis (AD). However, published findings have remained controversial. We investigated the association between early-life 25-hydroxyvitamin D $(25(\mathrm{OH}) \mathrm{D})$ levels and AD risk at childhood with a birth cohort. The data were obtained from "the Japan Environment and Children's Study (JECS)" and "the Sub-Cohort study of JECS" performed with children aged 2 years. "Liquid chromatography-tandem mass spectrometry" was used to measure VitD. The information on AD was obtained from parents' answers to a questionnaire when their children were aged 3 years. In order to explain the seasonal effects on VitD levels, a deseasonalized continuous variable was further calculated. The logistic regression models were fitted to evaluate the effect of VitD on childhood AD. The study included 4378 children with complete data on VitD and AD. The results from models indicated that low VitD at 2 years was not a risk factor for the development of AD at 3 years, after adjusting for potential confounders. Moreover, there was no U-shape relationship between deseasonalized VitD and childhood AD. Overall, early-life 25(OH)D levels were not link to the increased risk of developing childhood AD.

Keywords: 25-hydroxyvitamin D; vitamin D; deficiency; insufficiency; children; atopic dermatitis

\section{Introduction}

Atopic dermatitis (AD), also named atopic eczema, is the one of the most common chronic inflammatory skin disorders during childhood [1,2], with an estimated prevalence of around $10-30 \%$ among children. The development of AD has still remained incompletely understood, with studies showing the influence of genetic, environmental (e.g., pollen, house dust, and mites), and dietary factors [3,4].

Vitamin D (VitD) can be formed in the human skin through sunlight exposure or obtained from dietary intake [5-7]. It is essential for the maintenance of bone health [6,8], regulating calcium and phosphate metabolism [6,9]. Moreover, VitD is crucial in normal cutaneous physiology and immune response $[10,11]$ and appears to strengthen the epidermal barrier $[10,12]$. Studies also revealed that VitD promotes human cathelicidin generation, which has been considered insufficient in $\operatorname{AD}[10,13]$ and improves innate immunity. Given that the mechanism of development of AD relates to skin barrier dysfunction and immune response dysregulation [14,15], VitD might be related thereto. Epidemiological studies have also shown evidence with regard to VitD and the development of atopic eczema [16]. For instance, a trial performed among Mongolian children aged 2-17 years found that VitD supplementation appeared to improve AD among children [17]. Another study among 
adults also indicated that obese populations with VitD deficiency had higher risk for $\mathrm{AD}$ compared to those without VitD deficiency [18].

25-Hydroxyvitamin D $(25(\mathrm{OH}) \mathrm{D})$ is a stable VitD metabolite in the circulation [19]. Measurements of 25(OH)D have been considered to be a best approach for determining vitamin D status in the body [20].

Therefore, we designed this research study in order to address the issue involving early life 25(OH)D levels and childhood AD by using data from a large cohort dataset. Accordingly, we hypothesized that either low or high VitD levels would increase the odds of developing $\mathrm{AD}$ among young population.

\section{Methods}

\subsection{Population and Variables}

The participants included herein were recruited from a large birth cohort, namely “The Japan Environment and Children's Study (JECS)", with 104,062 fetal records [21,22]. The JECS primarily aimed to evaluate the relationship between "environmental exposure and children's health and development", with the design having been detailed elsewhere $[21,23,24]$. Briefly, JECS is an ongoing 13 year follow-up study. Pregnant women were recruited during 2011-2014 [25,26]. In addition to the main study, JECS also includes a Sub-Cohort Study with around 5000 participants [27].

The JECS protocol was reviewed and approved by "The Ministry of the Environment's Institutional Review Board on Epidemiological Studies" and "The Ethics Committees of all participating institutions (Ethical Number: No.100910001)" [26,28,29]. Data used for analysis were obtained from the jecs-ta-20190930-qsn and jecs-ta-20190930-mdv datasets [26].

The current study established a cohort to explore the relationship between vitamin D at 2 years and $\mathrm{AD}$ at 3 years. Participants with unknown pregnancy outcomes were excluded from analysis. Only singleton live born offspring who had complete data on VitD and the parents-reported AD at 3 years were included herein. Details regarding data selection are outlined in Figure 1.

Plasm 25(OH)D levels were measured using blood specimens collected from the participating children at 2 years. The total amount of blood collected was $4 \mathrm{~mL}$. "Liquid chromatography-tandem mass spectrometry (LC-MS/MS)" was used to measure $25(\mathrm{OH}) \mathrm{D}_{3}$ (cholecalciferol) and $25(\mathrm{OH}) \mathrm{D}_{2}$ (ergocalciferol) levels. Plasm $25(\mathrm{OH}) \mathrm{D}$ in this study amounts to the sum of ergocalciferol and cholecalciferol.

In order to explain the seasonal effects on VitD levels, a deseasonalized continuous variable was further calculated [30].

First, we built a "sinusoidal model" [30] as follows:

$$
25(\mathrm{OH}) \mathrm{D} \text { level }=\beta_{0}+\beta_{1} \sin \frac{2 \pi m}{12}+\beta_{2} \cos \frac{2 \pi m}{12}
$$

where $m$ indicated the timing of the test (month). Thereafter, residuals of the regression model were calculated for each individual. A seasonally adjusted value was the sum of the residual and overall mean.

Information on $\mathrm{AD}$ was obtained from the parents' answers to the questionnaire when their child turned 3 years old, which was based on a "modified Japanese-translated version of the International Study of Asthma and Allergies in Childhood (ISAAC)" and "was validated based on the ISAAC protocol for 6- to 7-year-old children" [26,31-33]. The detailed definition of $\mathrm{AD}$ has been described elsewhere [26]. 


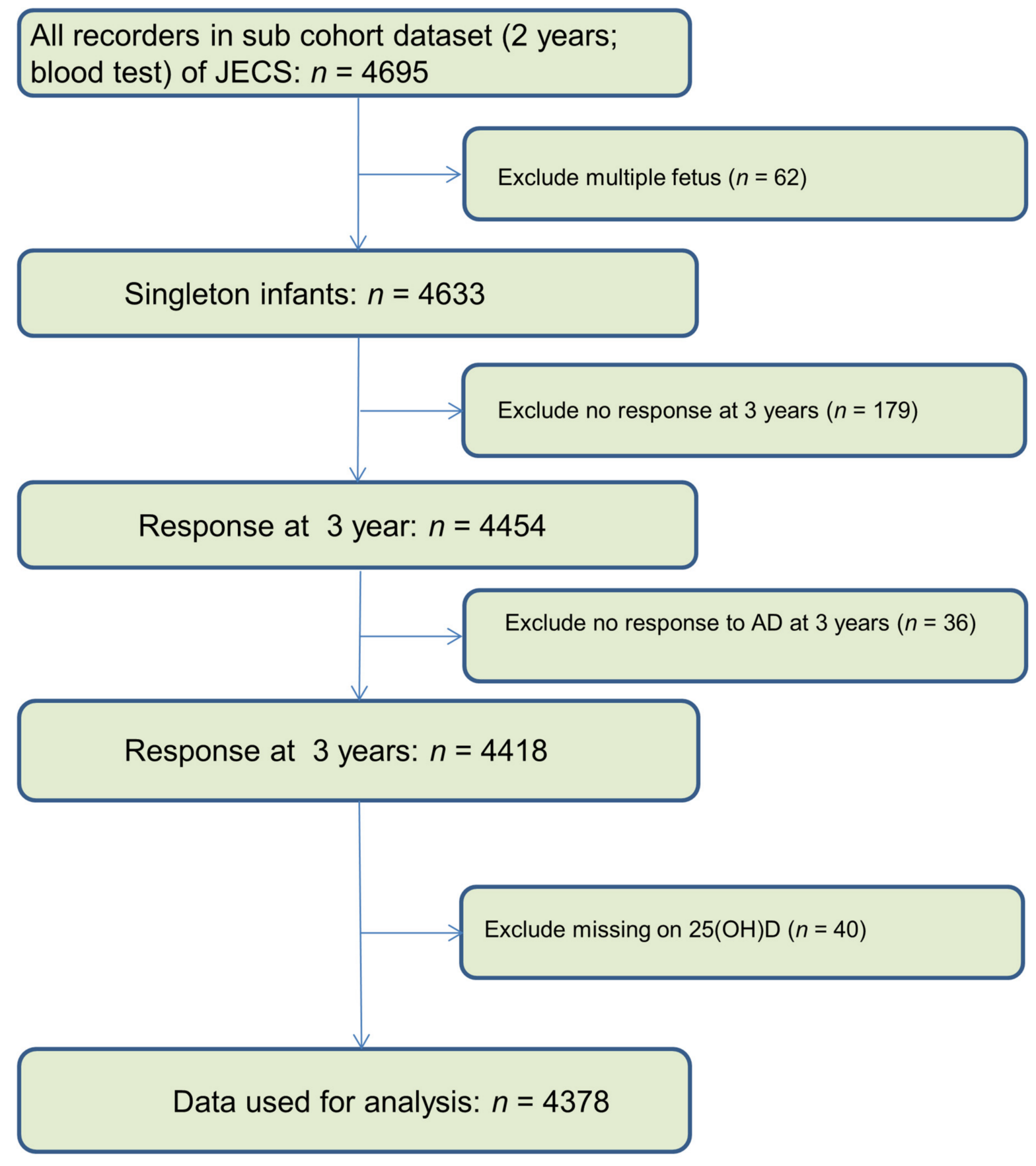

Figure 1. Flow chart of data selection.

The following were considered as potential confounders based on the previous studies: gender (boys/girls); z scores of body mass index (BMI) at 2 years; mother' age (<35 years / $\geq 35$ years); history of abnormality of pregnancy (no/yes); maternal smoking (no/yes); paternal smoking (no/yes); maternal history of AD (no/yes); maternal level of education (low/normal of high); family income; pet keeping (no/yes); pregnancy complications (no/yes); obstetric complications (no/yes); gestational age ( $<37$ weeks / $\geq 37$ weeks); BMI before pregnancy $(<25 / \geq 25)$; breast feeding (no/yes); kindergarten (no/yes); and parity (nulliparous/multipara). Variables (gender and parity) were transcribed from medical records after delivery. Others were transcribed from the questionnaire during pregnancy and after delivery. 


\subsection{Statistical Analysis}

The generalized linear models with the logit function (logistic regression models) were fitted for $\mathrm{AD}$ at age 3 years. We fitted two models with different confounding factors. The first model only adjusted for gender as the confounder, while the second model adjusted all the confounders mentioned above and the season in which the blood tests were conducted. Odds ratios (ORs) indicate the odds of reporting $A D$ versus no AD in children. We calculated the variance inflation factor in order to determine the collinearity in the models. The Wald tests were used to test the significance of the associations.

VitD at 2 years was grouped as deficiency, insufficiency and normal groups by using 20 and $30 \mathrm{ng} / \mathrm{mL}$ as the cut points. The deseasonalized VitD in the models was divided into five categories according to quantile (using the middle group as reference).

We assumed that the mechanisms of missingness were "missing at random" and used multiple imputation (MI) to deal with missing data [26,34]. A total of 20 data sets were generated and used for calculating pooled ORs. The variables in imputation models included all independent variables in the GLM when fitting AD.

Multiple test adjustment for $\mathrm{p}$ values was not conducted because of "the exploratory nature" of our report [26].

Logistic models with season adjusted values of VitD as continuous variables were further developed to explore nonlinear relationship between early life vitamin D and AD. "Restricted cubic splines" were used for the continuous variables in the models. We then plotted the graph with the $x$-axis as the deseasonalized VitD and the $y$-axis as the ORs ( $95 \% \mathrm{CI})$ of $\mathrm{AD}$. In addition, the analysis was repeated by including only those with complete data on $\mathrm{AD}$ and all the independent variables. We also assessed the modified effect of "maternal history of AD". Finally, subgroup analysis was performed. The model was rerun among children without $\mathrm{AD}$ at 1 and 2 years.

All calculations were carried out with R software (version 4.0.3) [35].

\section{Results}

\subsection{Participant Characteristics}

The distribution of covariates among those included and excluded from analysis is summarized in Table S1. There were no significant differences between the two groups. The prevalence of $\mathrm{AD}$ was $13.3 \%$ in children aged 3 years. The median (interquartile range) of VitD was 24.6 (8.5) $\mathrm{ng} / \mathrm{mL}$.

\subsection{VitD and Childhood Atopic Dermatitis}

The odds ratios for serum $25(\mathrm{OH}) \mathrm{D}$ levels from the logistic models are listed in Table 1 After adjusting for confounders, VitD deficiency (OR: $0.97 ; 95 \%$ CI: (0.74-1.27)) or insufficiency (OR: $0.92 ; 95 \%$ CI: (0.73-1.14)) did not increase the possibility of childhood AD. Compared to reference group (category 3), low (category 1 and 2) or high levels (category 4 and 5) of deseasonalized VitD showed no marked effect on childhood AD (Table 2).

Table 1. Odds ratios from the logistic regression model for early life vitamin D levels and childhood atopic dermatitis.

\begin{tabular}{|c|c|c|}
\hline 25(OH)D (ng/mL) & Odds Ratios $(95 \% \mathrm{CI}) \$$ & 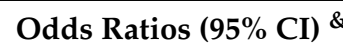 \\
\hline \multicolumn{3}{|l|}{ ALL } \\
\hline$<20$ vs. $\geq 30$ & $1.06(0.83-1.35)$ & $0.97(0.74-1.27)$ \\
\hline$\geq 20$ and $<30$ vs. $\geq 30$ & $0.96(0.77-1.19)$ & $0.92(0.73-1.14)$ \\
\hline \multicolumn{3}{|l|}{ Sub dataset $\#$} \\
\hline$<20$ vs. $\geq 30$ & $1.25(0.79-1.98)$ & $1.23(0.75-2.03)$ \\
\hline$\geq 20$ and $<30$ vs. $\geq 30$ & $1.22(0.82-1.83)$ & $1.21(0.80-1.83)$ \\
\hline
\end{tabular}

CI: confidential inference. ${ }^{\#}$ Analysis was limited to those without atopic dermatitis at 1 and 2 years. ${ }^{\$}$ Adjusted for gender as a confounder. \& Adjusted for all confounders listed in Table S1. 
Table 2. Odds ratios from the logistic regression model for deseasonalized vitamin D levels.

\begin{tabular}{lcc}
\hline \multicolumn{1}{c}{ Deseasonalized 25(OH)D } & ORs (95\% CI) & ORs (95\% CI) \& \\
\hline All & & \\
Deseasonalized 25(OH)D category 1 vs. 3 & $0.91(0.69-1.20)$ & $0.91(0.69-1.21)$ \\
Deseasonalized 25(OH)D category 2 vs. 3 & $0.92(0.70-1.21)$ & $0.95(0.72-1.26)$ \\
Deseasonalized 25(OH)D category 4 vs. 3 & $0.92(0.70-1.21)$ & $0.89(0.67-1.17)$ \\
Deseasonalized 25(OH)D category 5 vs. 3 & $0.93(0.71-1.22)$ & $0.94(0.71-1.23)$ \\
Sub dataset \# & & \\
Deseasonalized 25(OH)D category 1 vs. 3 & $0.89(0.57-1.41)$ & $0.90(0.57-1.42)$ \\
Deseasonalized 25(OH)D category 2 vs. 3 & $0.70(0.43-1.14)$ & $0.72(0.44-1.17)$ \\
Deseasonalized 25(OH)D category 4 vs. 3 & $0.80(0.51-1.28)$ & $0.79(0.50-1.27)$ \\
Deseasonalized 25(OH)D category 5 vs. 3 & $0.64(0.39-1.05)$ & $0.65(0.40-1.07)$ \\
\hline
\end{tabular}

ORs: odds ratios; CI: confidential inference. \# Analysis was limited to those without AD at 1 and 2 years.

\$ Adjusted for gender as a confounder. \& Adjusted for all confounders listed in Table S1.

\subsection{Sensitivity Analyses}

There was no modified effect of "maternal history of AD". Stratified analysis by this variable showed similar non-significant ORs (Table S2). The results from models fitting the complete data showed very similar results (data not shown). When analysis was limited to those without $\mathrm{AD}$ at 1 and 2 years, no obvious significant association were observed (Table 2). After further adjusting for season in the models, deseasonalized VitD showed no marked effect on $\mathrm{AD}$ (results not shown). No significant U-shape relationship was found when the variable deseasonalized VitD was placed into the models as a continuous variable (Figure 2).

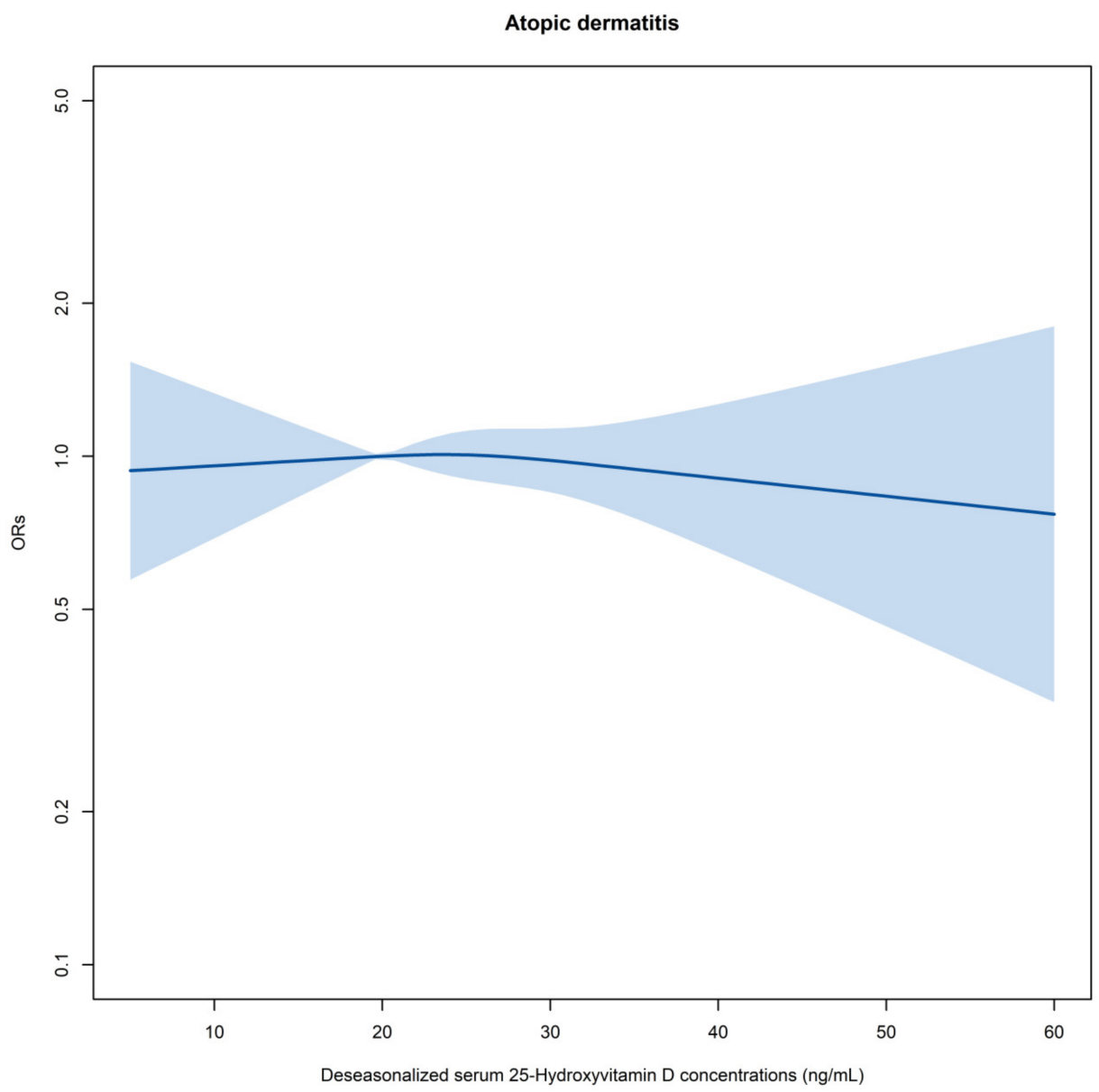

Figure 2. Summary of logistic regression models for estimating the relationship between deseasonalized vitamin D and atopic dermatitis in early childhood. Deseasonalized vitamin D was treated as a continuous variable. Model adjusted for all confounders listed in Table S1. Reference for ORs: $20 \mathrm{ng} / \mathrm{mL}$. Shaded bands: 95\% confidence limits for ORs. ORs: odds ratios. 


\section{Discussion}

The current study found no evidence to support the hypothesis that lower VitD levels increase the odds of developing AD during early childhood. Moreover, VitD level at 2 years was unable to predict $\mathrm{AD}$ at 3 years among children without $\mathrm{AD}$ at 1-2 years. This has been the first effort to evaluate this association with a representative Japanese cohort.

To date, limited reports have been made available on the issue involving early life VitD and childhood AD. Some published reports have suggested that maternal VitD measured before pregnancy, during pregnancy, or at delivery were not associated with increased odds in the development childhood AD $[1,11,36,37]$. A cohort study in Norway found that vitamin D in children aged 0-2 years was not significantly related to caregiver-reported atopic eczema [38]. Our results are also similar to some published cross-sectional studies. For example, Cairncross et al. demonstrated that $25(\mathrm{OH}) \mathrm{D}$ concentrations did not change the odds of eczema in children aged 2-5 years in New Zealand [39]. A recently published cross-sectional study in Germany by Reinehr et al. compared VitD levels between children with and without $\mathrm{AD}$ and found no significant differences between the two groups [40].

Other studies, however, have published conflicting conclusions, with increased eczema risk being associated with low/high VitD levels. Accordingly, Heimbeck et al. found that low VitD status is inversely related to eczema based on evidence from children aged 1-17 in a cross-sectional survey in Germany [41]. Meanwhile, a study performed in the UK by Gale et al. indicated that children whose mothers had $25(\mathrm{OH}) \mathrm{D}$ concentrations higher than $75 \mathrm{nmol} / \mathrm{L}$ during pregnancy were more likely to have atopic eczema at age 9 months compared to those exposed to normal VitD levels [42]. By contrast, Jone et al. found that infant with higher cord blood VitD had reduced odds of developing eczema at 6-12 months [43]. The current study did not find similar results. The differences in results involving this issue may have been attributed to differences in the study population and sample sizes, outcome definitions, and the time points at which $25(\mathrm{OH}) \mathrm{D}$ was measured. Further cohort studies are still needed in order to replicate and confirm our findings.

Although the aforementioned studies implied that lower VitD levels may promote increased or decreased $\mathrm{AD}$ in children, our findings did not observe any similar evidence in the younger Japanese population. Other environmental/genetic factors, such as filaggrin loss-of-function mutations, seem to be more important in explaining childhood AD [44]. UV-B is another important confounder when investigating whether VitD deficiency results in increased risk of childhood AD. Future studies are necessary to evaluate the effects of genetic and environmental factors on the development of AD among children [45].

Our study has some limitations. Firstly, information on AD was collected by parents by using questionnaires. For this reason, some misclassifications of AD could still exist due to the lack of validation from physical examination or medical records, which might have reduced the power of this study. However, the "ISAAC questionnaire" is commonly used in large epidemiological studies and has been proven to have good internal consistency [26]. Secondly, we could not adjust for some important confounder, such as sunlight exposure and supplementation intake, due to the lack of data in the JECS. Thirdly, VitD was measured only once. We do not think this could bias our results significantly. Saliba et al., who investigated the correlation between values measured 1 year apart in the same month of the year among participants who had not used supplements 6 months before blood sampling, reported a good consistency [46]. Finally, negative results could also be attributed to uninvestigated variables or other environmental and genetic confounders that have not yet been identified.

In conclusion, although the results from animal models and epidemiology studies imply a relationship between VitD and childhood AD, our findings suggest no such association among Japanese children aged 2 years. Further longitudinal studies investigating other environmental/genetic factors are still needed to confirm the results in this study. Moreover, future studies should focus on other active forms of VitD, such as 1,25-dihydroxyvitamin $\mathrm{D}$, in order to evaluate this topic again. 
Supplementary Materials: The following are available online at https: / www.mdpi.com/article/ 10.3390/nu13082761/s1, Table S1: Distribution of covariates among those included and excluded from analysis according to the selection criteria, Table S2: Modified effect of maternal history of atopic dermatitis.

Author Contributions: L.Y. conceptualized and designed the study to which M.S., M.S.-A., M.N., H.M., K.Y.-H. and Y.O. provided advice. L.Y., H.M., K.Y.-H. and Y.O. collected the data. L.Y. analyzed the data and wrote the manuscript. L.Y., M.S., M.S.-A., M.N., H.M., K.Y.-H. and Y.O. and The JECS Group reviewed the manuscript and provided critical advice. All authors have read and agreed to the published version of the manuscript.

Funding: This study was funded by "the Ministry of the Environment, Japan".

Institutional Review Board Statement: The study was conducted according to the guidelines of the Declaration of Helsinki. The JECS protocol was reviewed and approved by the Ministry of the Environment's Institutional Review Board on Epidemiological Studies (No.100406001, 6 April 2010) and by the Ethics Committees of all participating institutions.

Informed Consent Statement: All participants included in the JECS signed a consent form.

Data Availability Statement: Data are not permitted for public deposition.

Acknowledgments: We thank the participating children and their families registered in the JECS. We thank all staff members who contributed to data collection. The conclusions of this manuscript are the sole responsibility of the authors. Members of the JECS Group as of 2021 include the following: ichihiro Kamijima (principal investigator, Nagoya City University, Nagoya, Japan), Shin Yamazaki (National Institute for Environmental Studies, Tsukuba, Japan), Yukihiro Ohya (National Center for Child Health and Development, Tokyo, Japan), Reiko Kishi (Hokkaido University, Sapporo, Japan), Nobuo Yaegashi (Tohoku University, Sendai, Japan), Koichi Hashimoto (Fukushima Medical University, Fukushima, Japan), Chisato Mori (Chiba University, Chiba, Japan), Shuichi Ito (Yokohama City University, Yokohama, Japan), Zentaro Yamagata (University of Yamanashi, Chuo, Japan), Hidekuni Inadera (University of Toyama, Toyama, Japan), Takeo Nakayama (Kyoto University, Kyoto, Japan), Hiroyasu Iso (Osaka University, Suita, Japan), Masayuki Shima (Hyogo College of Medicine, Nishinomiya, Japan), Youichi Kurozawa (Tottori University, Yonago, Japan), Narufumi Suganuma (Kochi University, Nankoku, Japan), Koichi Kusuhara (University of Occupational and Environmental Health, Kitakyushu, Japan), and Takahiko Katoh (Kumamoto University, Kumamoto, Japan).

Conflicts of Interest: All authors have no conflict of interest.

\section{Abbreviations}

Vitamin D: VitD; JECS: Japan Environment and Children's Study; ISAAC: International Study of Asthma and Allergies in Childhood; OR: odds ratio; CI: confidence interval; AD: atopic dermatitis.

\section{References}

1. Gazibara, T.; Elbert, N.J.; den Dekker, H.T.; de Jongste, J.C.; Reiss, I.; McGrath, J.J.; Eyles, D.W.; Burne, T.H.; Tiemeier, H.; Jaddoe, V.W.; et al. Associations of maternal and fetal 25-hydroxyvitamin D levels with childhood eczema: The Generation R Study. Pediatr. Allergy Immunol. 2016, 27, 283-289. [CrossRef] [PubMed]

2. Avena-Woods, C. Overview of atopic dermatitis. Am. J. Manage. Care 2017, 23, S115-S123.

3. Yamamoto-Hanada, K.; Yang, L.; Saito-Abe, M.; Sato, M.; Inuzuka, Y.; Toyokuni, K.; Nishimura, K.; Irahara, M.; Ishikawa, F.; Miyaji, Y.; et al. Four phenotypes of atopic dermatitis in Japanese children: A general population birth cohort study. Allergol. Int. 2019, 68, 521-523. [CrossRef] [PubMed]

4. Yamamoto-Hanada, K.; Pak, K.; Saito-Abe, M.; Yang, L.; Sato, M.; Irahara, M.; Mezawa, H.; Sasaki, H.; Nishizato, M.; Ishitsuka, K.; et al. Allergy and immunology in young children of Japan: The JECS cohort. World Allergy Organ. J. 2020, 13, 100479. [CrossRef]

5. Zhang, R.; Naughton, D.P. Vitamin D in health and disease: Current perspectives. Nutr. J. 2010, 9, 65. [CrossRef]

6. Braegger, C.; Campoy, C.; Colomb, V.; Decsi, T.; Domellof, M.; Fewtrell, M.; Hojsak, I.; Mihatsch, W.; Molgaard, C.; Shamir, R.; et al. Vitamin D in the healthy European paediatric population. J. Pediatr. Gastroenterol. Nutr. 2013, 56, 692-701. [CrossRef]

7. Sanmartin, R.; Pardos, C.; Doste, D.; Aguilera, J.; Alijarde, R.; Agon-Banzo, P.J.; Garcia-Malinis, A.J.; Puzo, J.; Hernandez-Martin, A.; Gilaberte, Y. The association between atopic dermatitis and serum 25-hydroxyvitamin D in children: Influence of sun exposure, diet, and atopy features-A cross-sectional study. Pediatr. Dermatol. 2020, 37, 294-300. [CrossRef]

8. DeLuca, H.F.; Schnoes, H.K. Vitamin D: Recent advances. Annu. Rev. Biochem. 1983, 52, 411-439. [CrossRef] 
9. Chung, M.; Balk, E.M.; Brendel, M.; Ip, S.; Lau, J.; Lee, J.; Lichtenstein, A.; Patel, K.; Raman, G.; Tatsioni, A.; et al. Vitamin D and calcium: A systematic review of health outcomes. Evid. Rep. Technol. Assess. 2009, 183, 1-420.

10. Chiu, Y.E.; Havens, P.L.; Siegel, D.H.; Ali, O.; Wang, T.; Holland, K.E.; Galbraith, S.S.; Lyon, V.B.; Drolet, B.A. Serum 25-hydroxyvitamin D concentration does not correlate with atopic dermatitis severity. J. Am. Acad. Dermatol. 2013, 69, 40-46. [CrossRef]

11. Wills, A.K.; Shaheen, S.O.; Granell, R.; Henderson, A.J.; Fraser, W.D.; Lawlor, D.A. Maternal 25-hydroxyvitamin D and its association with childhood atopic outcomes and lung function. Clin. Exp. Allergy 2013, 43, 1180-1188. [CrossRef]

12. Bikle, D.D. Vitamin D metabolism and function in the skin. Mol. Cell. Endocrinol. 2011, 347, 80-89. [CrossRef]

13. Wang, T.T.; Nestel, F.P.; Bourdeau, V.; Nagai, Y.; Wang, Q.; Liao, J.; Tavera-Mendoza, L.; Lin, R.; Hanrahan, J.W.; Mader, S.; et al. Cutting edge: 1,25-dihydroxyvitamin D3 is a direct inducer of antimicrobial peptide gene expression. J. Immunol. 2004, 173, 2909-2912. [CrossRef]

14. Bieber, T. Atopic dermatitis. N. Engl. J. Med. 2008, 358, 1483-1494. [CrossRef]

15. Yue, H.; Umehara, Y.; Trujillo-Paez, J.V.; Peng, G.; Nguyen, H.L.T.; Chieosilapatham, P.; Kiatsurayanon, C.; Song, P.; Okumura, K.; Ogawa, H.; et al. Exogenous factors in the pathogenesis of atopic dermatitis: Irritants and cutaneous infections. Clin. Exp. Allergy 2021, 51, 382-392. [CrossRef]

16. Palmer, D.J. Vitamin D and the Development of Atopic Eczema. J. Clin. Med. 2015, 4, 1036-1050. [CrossRef]

17. Camargo, C.A., Jr.; Ganmaa, D.; Sidbury, R.; Erdenedelger, K.; Radnaakhand, N.; Khandsuren, B. Randomized trial of vitamin D supplementation for winter-related atopic dermatitis in children. J. Allergy Clin. Immunol. 2014, 134, 831-835.e1. [CrossRef]

18. Oren, E.; Banerji, A.; Camargo, C.A., Jr. Vitamin D and atopic disorders in an obese population screened for vitamin D deficiency. J. Allergy Clin. Immunol. 2008, 121, 533-534. [CrossRef]

19. Christakos, S.; Ajibade, D.V.; Dhawan, P.; Fechner, A.J.; Mady, L.J. Vitamin D: Metabolism. Endocrinol. Metab. Clin. N. Am. 2010, 39, 243-253. [CrossRef]

20. Muehleisen, B.; Gallo, R.L. Vitamin D in allergic disease: Shedding light on a complex problem. J. Allergy Clin. Immunol. 2013, 131, 324-329. [CrossRef]

21. Kawamoto, T.; Nitta, H.; Murata, K.; Toda, E.; Tsukamoto, N.; Hasegawa, M.; Yamagata, Z.; Kayama, F.; Kishi, R.; Ohya, Y.; et al. Rationale and study design of the Japan environment and children's study (JECS). BMC Public Health 2014, 14, 25. [CrossRef] [PubMed]

22. Kawanishi, Y.; Saijo, Y.; Yoshioka, E.; Nakagi, Y.; Yoshida, T.; Miyamoto, T.; Sengoku, K.; Ito, Y.; Miyashita, C.; Araki, A.; et al. The Association between Prenatal Yoga and the Administration of Ritodrine Hydrochloride during Pregnancy: An Adjunct Study of the Japan Environment and Children's Study. PLoS ONE 2016, 11, e0158155. [CrossRef] [PubMed]

23. Saito, M.; Yamamoto-Hanada, K.; Pak, K.; Ayabe, T.; Mezawa, H.; Ishitsuka, K.; Konishi, M.; Yang, L.; Matsumoto, K.; Saito, H.; et al. Having small-for-gestational-age infants was associated with maternal allergic features in the JECS birth cohort. Allergy 2018, 73, 1908-1911. [CrossRef] [PubMed]

24. Yamamoto-Hanada, K.; Ishitsuka, K.; Pak, K.; Saito, M.; Ayabe, T.; Mezawa, H.; Konishi, M.; Yang, L.; Matsumoto, K.; Saito, H.; et al. Allergy and mental health among pregnant women in the Japan Environment and Children's Study. J. Allergy Clin. Immunol. Pract. 2018, 6, 1421-1424.e2. [CrossRef]

25. Komori, K.; Komori, M.; Eitoku, M.; Muchanga, S.M.J.; Ninomiya, H.; Kobayashi, T.; Suganuma, N.; Japan Environment and Children's Study (JECS) Group. Verbal abuse during pregnancy increases frequency of newborn hearing screening referral: The Japan Environment and Children's Study. Child Abus. Negl. 2019, 90, 193-201. [CrossRef]

26. Yang, L.; Sato, M.; Saito-Abe, M.; Irahara, M.; Nishizato, M.; Sasaki, H.; Konishi, M.; Ishitsuka, K.; Mezawa, H.; Yamamoto-Hanada, K.; et al. Association of Hemoglobin and Hematocrit Levels during Pregnancy and Maternal Dietary Iron Intake with Allergic Diseases in Children: The Japan Environment and Children's Study (JECS). Nutrients 2021, 13, 810. [CrossRef]

27. Sekiyama, M.; Yamazaki, S.; Michikawa, T.; Nakayama, S.F.; Nitta, H.; Taniguchi, Y.; Suda, E.; Isobe, T.; Kobayashi, Y.; Iwai-Shimada, M.; et al. Study design and participants' profile in the Sub-Cohort Study in the Japan Environment and Children's Study (JECS). J. Epidemiol. 2020, JE20200448. [CrossRef]

28. Matsumura, K.; Hamazaki, K.; Tsuchida, A.; Inadera, H.; The Japan Environment and Children's Study (JECS) Group. House Dust Avoidance during Pregnancy and Subsequent Infant Development: The Japan Environment and Children's Study. Int. J. Environ. Res. Public Health 2021, 18, 4277. [CrossRef]

29. Minatoya, M.; Araki, A.; Miyashita, C.; Itoh, S.; Kobayashi, S.; Yamazaki, K.; Bamai, Y.A.; Saijyo, Y.; Ito, Y.; Kishi, R.; et al. Cat and Dog Ownership in Early Life and Infant Development: A Prospective Birth Cohort Study of Japan Environment and Children's Study. Int. J. Environ. Res. Public Health 2019, 17, 205. [CrossRef]

30. Van der Mei, I.A.; Ponsonby, A.L.; Dwyer, T.; Blizzard, L.; Taylor, B.V.; Kilpatrick, T.; Butzkueven, H.; McMichael, A.J. Vitamin D levels in people with multiple sclerosis and community controls in Tasmania, Australia. J. Neurol. 2007, 254, 581-590. [CrossRef]

31. Asher, M.I.; Keil, U.; Anderson, H.R.; Beasley, R.; Crane, J.; Martinez, F.; Mitchell, E.A.; Pearce, N.; Sibbald, B.; Stewart, A.W.; et al. International Study of Asthma and Allergies in Childhood (ISAAC): Rationale and methods. Eur. Respir. J. 1995, 8, 483-491. [CrossRef] 
32. Weiland, S.K.; Bjorksten, B.; Brunekreef, B.; Cookson, W.O.; von Mutius, E.; Strachan, D.P.; International Study of Asthma and Allergies in Childhood Phase II Study Group. Phase II of the International Study of Asthma and Allergies in Childhood (ISAAC II): Rationale and methods. Eur. Respir. J. 2004, 24, 406-412. [CrossRef]

33. Ellwood, P.; Asher, M.I.; Beasley, R.; Clayton, T.O.; Stewart, A.W.; ISAAC Steering Committee. The international study of asthma and allergies in childhood (ISAAC): Phase three rationale and methods. Int. J. Tuberc. Lung Dis. 2005, 9, 10-16.

34. Buuren, S.V.; Groothuis, O.K. mice: Multivariate Imputation by Chained Equations in R. J. Stat. Softw. 2011, 45, 1-67. [CrossRef]

35. R Core Team. R: A Language and Environment for Statistical Computing; R Foundation for Statistical Computing: Vienna, Austria, 2020. Available online: https://www.R-project.org/. (accessed on 8 August 2021).

36. Boyle, V.T.; Thorstensen, E.B.; Thompson, J.M.D.; McCowan, L.M.E.; Mitchell, E.A.; Godfrey, K.M.; Poston, L.; Wall, C.R.; Murphy, R.; Cutfield, W.; et al. The relationship between maternal 25-hydroxyvitamin D status in pregnancy and childhood adiposity and allergy: An observational study. Int. J. Obes. 2017, 41, 1755-1760. [CrossRef]

37. Hennessy, A.; Hourihane, J.O.; Malvisi, L.; Irvine, A.D.; Kenny, L.C.; Murray, D.M.; Kiely, M.E. Antenatal vitamin D exposure and childhood eczema, food allergy, asthma and allergic rhinitis at 2 and 5 years of age in the atopic disease-specific Cork BASELINE Birth Cohort Study. Allergy 2018, 73, 2182-2191. [CrossRef]

38. Berents, T.L.; Carlsen, K.C.L.; Mowinckel, P.; Sandvik, L.; Skjerven, H.O.; Rolfsjord, L.B.; Kvenshagen, B.; Hunderi, J.O.; Bradley, M.; Lieden, A.; et al. Vitamin D levels and atopic eczema in infancy and early childhood in Norway: A cohort study. Br. J. Dermatol. 2016, 175, 95-101. [CrossRef]

39. Cairncross, C.; Grant, C.; Stonehouse, W.; Conlon, C.; McDonald, B.; Houghton, L.; Eyles, D.; Camargo, C.A.; Coad, J.; von Hurst, P. The Relationship between Vitamin D Status and Allergic Diseases in New Zealand Preschool Children. Nutrients $2016,8,326$. [CrossRef]

40. Reinehr, T.; Langrock, C.; Hamelmann, E.; Lucke, T.; Koerner-Rettberg, C.; Holtmann, M.; Legenbauer, T.; Gest, S.; Frank, M.; Schmidt, B.; et al. 25-Hydroxvitamin D concentrations are not lower in children with bronchial asthma, atopic dermatitis, obesity, or attention-deficient/hyperactivity disorder than in healthy children. Nutr. Res. 2018, 52, 39-47. [CrossRef]

41. Heimbeck, I.; Wjst, M.; Apfelbacher, C.J. Low vitamin D serum level is inversely associated with eczema in children and adolescents in Germany. Allergy 2013, 68, 906-910. [CrossRef]

42. Gale, C.R.; Robinson, S.M.; Harvey, N.C.; Javaid, M.K.; Jiang, B.; Martyn, C.N.; Godfrey, K.M.; Cooper, C.; Princess Anne Hospital Study Group. Maternal vitamin D status during pregnancy and child outcomes. Eur. J. Clin. Nutr. 2008, 62, 68-77. [CrossRef]

43. Jones, A.P.; D’Vaz, N.; Meldrum, S.; Palmer, D.J.; Zhang, G.; Prescott, S.L. 25-hydroxyvitamin D3 status is associated with developing adaptive and innate immune responses in the first 6 months of life. Clin. Exp. Allergy 2015, 45, 220-231. [CrossRef]

44. Koseki, R.; Morii, W.; Noguchi, E.; Ishikawa, M.; Yang, L.; Yamamoto-Hanada, K.; Narita, M.; Saito, H.; Ohya, Y. Effect of filaggrin loss-of-function mutations on atopic dermatitis in young age: A longitudinal birth cohort study. J. Hum. Genet. $2019,64,911-917$. [CrossRef]

45. Hattori, H.; Kitamura, A.; Takahashi, F.; Kobayashi, N.; Sato, A.; Miyauchi, N.; Nishigori, H.; Mizuno, S.; Sakurai, K.; Ishikuro, M.; et al. The risk of secondary sex ratio imbalance and increased monozygotic twinning after blastocyst transfer: Data from the Japan Environment and Children's Study. Reprod. Biol. Endocrinol. 2019, 17, 27. [CrossRef]

46. Saliba, W.; Barnett, O.; Stein, N.; Kershenbaum, A.; Rennert, G. The longitudinal variability of serum 25(OH)D levels. Eur. J. Intern. Med. 2012, 23, e106-e111. [CrossRef] 